\title{
Terrorism and the Infinite Bargaining Model
}

Alexander Farrow is an undergraduate at Harvard University, concerntrating in Government with a focus on national security.

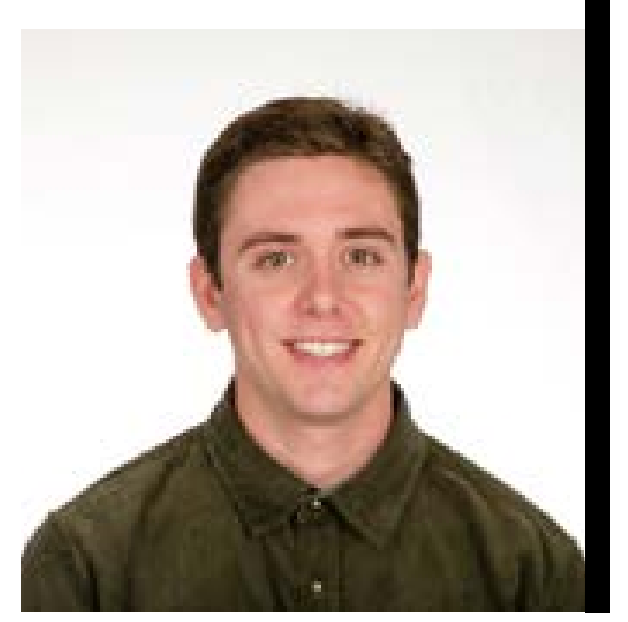

FROM THE Ku Klux Klan's lynchings to al Qaeda's World Trade Center attacks, terrorist organizations have historically exploited fear and destruction to achieve their end goals. Attacking both a nation's government and population, terrorist organizations inflict damage on their intended audiences, or targets. ${ }^{1}$ This paper explores how terrorist organizations interact with their targets. In my analysis, I assume complete rationality and build an infinite bargaining model of political concession between both actors. I claim that terrorist organizations bargain with targets in the long run by increasing the payoffs for cooperation and decreasing the payoffs for noncooperation.

\section{Rational Bargaining}

Terrorism refers to the "the unlawful use of force of violence against persons or property to intimidate or coerce a government, the civilian population, or any segment thereof, in furtherance of political or social objectives". ${ }^{2}$ I define a terrorist organization, therefore, as an organization that uses terrorism to achieve its objectives.

Relevant scholarly literature establishes that terrorist organizations often bargain with the group from which they desire political concessions-the classic bargaining model of terrorism. ${ }^{3}$ Furthermore, they manipulate the target's utility function in order to coerce concessions from the target. ${ }^{4}$ Specific goalsregime change, territorial control, policy change, social influence, and/or status quomotivate terrorist organizations to manipulate the political sphere. ${ }^{5}$ Hezbollah, for example, seeks to evict Israel from Lebanon (territorial control) and establish a Palestinian Islamic state (regime change). Al-Qaeda in Iraq seeks to diminish US influence (policy control) and establish an Iraqi state (regime change).

However, the main counterargument to the bargaining model is that these uses of force sometimes result in no political concessions. "A major puzzle for the model, then, is that although terrorism is by definition scary and destructive, organizations rarely if ever attain their policy demands by targeting civilians". ${ }^{6}$ Not only can attacks sometimes yield zero political gains, but they may also cause the target to vehemently oppose conceding to the terrorist organization. The Irish Republican Army's attack on the public, for example, rekindled British commitment to imperialism. The ISIL beheadings of journalists, such as James Foley, undoubtedly redoubled American commitment to airstrikes. ${ }^{7}$

My claim is that an infinite bargaining model better illustrates rational bargaining. Terrorist organizations not only bargain for immediate concessions, but also increase their capacity 


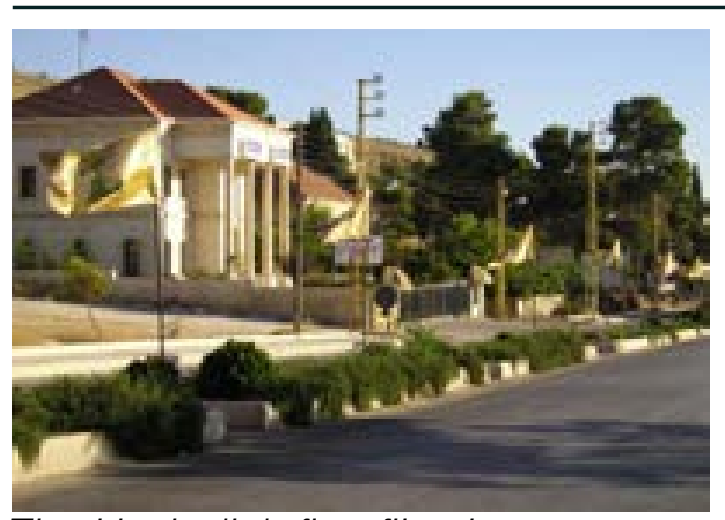

The Hezbollah flag flies in a street.

to bargain for future concessions by coercing long-term cooperation with their targets. In the following sections, I will outline the conditions for infinite bargaining and clarify how terrorist organizations increase payoffs for cooperation and decrease payoffs for noncooperation.

\section{The Infinite Bargaining Model}

In this model, the terrorist organization and the target have two strategies: to cooperate (c) or not (c) with one another. By cooperating, I refer to the act of conceding to the other actor's specific end goal. Note also that the strategy set is (target strategy, terrorist strategy). The two actors play a bargaining game similar to the Prisoner's Dilemma because $(C, C)$ yields mutual political gains, $(\overline{c, C})$ yields lowered political gains, and any deviation yields increased political gains for one actor and none for the other. $(\bar{c}, \mathrm{C})$ is not efficient, as the terrorist organization cannot achieve end goals when the target does not concede. $(c, c)$ is not as efficient, as the target cannot cheaply sustain its end goals when the terrorist organization does not concede. The only way that both actors receive significant political concessions, therefore, is to cooperate with one another, $(c, c)$. However, in a finite game, there is an incentive for each actor to be noncooperative, resulting in Nash equilibrium at $\left(\overline{\left.C^{-}, C^{-}\right)}\right.$.

\section{In a finite game there is an incentive for each actor to be noncooperative... an infinite bargaining model explains mutual cooperation as a sub- game Nash equilibrium.}

As I will illustrate, an infinite bargaining model explains mutual cooperation as a subgame Nash equilibrium. The necessary preconditions for this model are (1) the game is played an infinite amount of times and (2) the players value future payoffs. ${ }^{8}$ The first condition for cooperation is the initiation of an infinite game. Historically, terrorist organizations initiate an infinite game by signaling their commitment to longevity. Abrahms, for example, outlines that terrorist organizations "survive for decades, notwithstanding their political futility". 9 Even organizations that attain large political concessions do not necessarily disband. Hezbollah, for example, continues to thrive even after successfully liberating southern Lebanon (2000) with guerrilla attacks on Israeli Defense Forces. Other terrorist organizations, such as the Red Army Faction in Germany, even dynamically morph their political objectives after exhausting a conflict. ${ }^{10}$ And even if they attain their immediate goals, terrorist organizations prolong their activities in order to push the game into infinite play.

The next condition for infinite play is weighted value for future utility. I define $d$ as the discount factor, or a variable determining how much preference an actor gives to future payoffs $(0<d<1)$. A higher $d$ indicates more preference to future utility. Terrorist 
organizations, therefore, must establish a condition for which cooperation for infinity yields more utility to the target than deviating for one period and acting at Nash equilibrium for every period after that. The condition is modeled with the following utility inequality for the target:

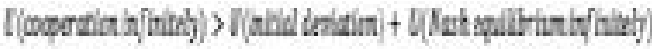

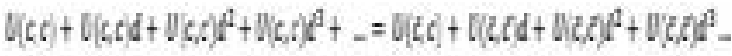 $\left.\frac{U(c, c)}{1-d}>U(i, c)+i \frac{U(i, c)}{1-d}\right]$, gival $<d<1$}

If the above condition holds true, a target will value cooperating at the grim-trigger strategy of $(c, c)$ over infinite noncooperation. There are a variety of historical examples in which this has played out, including the withdrawal of US forces in Lebanon after the attacks on the Marine barracks in Beirut and the Philippine withdrawal of troops after a kidnapping. ${ }^{11}$ Furthermore, more than half of all suicide bombings result in some political concessions by the target.12 Some organizations even maintain enduring relationships with "high level" leadership in the target, resulting in continued gains. For example, Hamas and Iran form a sort of long-term strategic alliance, exchanging political leverage in Palestine for funding. ${ }^{13}$ Whether terrorist organizations secure catalytic temporary gains or cooperative long-term gains, they can coerce a target to cooperation.

\section{Payoffs for Mutual Cooperation}

In order to maintain long-term bargaining capacity, terrorist organizations increase targets' payoffs for mutual cooperation, $U(c, c)$. Terrorist organizations can do this by providing support and resources to the target in four distinct areas: politics, economics, society, and ideology. ${ }^{14}$ In terms of providing political utility, terrorists can provide a number of resources, including security and political leverage. Hezbollah is a prime example of a terrorist organization that provides political leverage to Iran. Because Hezbollah and Iran share common sentiment about the political sphere of the Middle East, Hezbollah acts as Iran's asymmetric political puppet in regions like Lebanon in exchange for Iranian resources, funding, and support. ${ }^{15}$

Terrorist organizations also provide economic incentives for cooperation. Establishing social welfare programs, funding political parties, and stimulating the target's economy are all ways that these organizations can manipulate economic incentives. Hamas, for example, spends \$50-70 million a year on social services in Palestine in order to bolster support. $^{16}$ This subsidiary Islamic NGO, therefore, distributes "money, clothes, and food" to the target's population. ${ }^{17}$ Because Gaza's unemployment rate hovers around $50 \%$ and Israel blockades international humanitarian relief, the population covets these social services. Hamas, therefore, attempts to buy off the population's support with increased economic utility. Consequently, the Palestinian population has increased its support of Hamas.

Additionally, terrorist organizations manipulate social incentives through familial ties and friendship networks. Psychological analysis suggests that some terrorists join these organizations "to develop strong affective ties with fellow terrorists"; these organizations provide a bond of solidarity to "unmarried young men or widowed women who were not gainfully employed prior to joining". ${ }^{18}$ Furthermore, having a friend or relative in a group, like al-Qaeda or Hezbollah, heavily influences a recruit's decision to join that organization. In other words, recruits join because they desire the familial affirmation and social network that the organization provides. Terrorism, in this way, is a social activity. 


\section{There is an incentive for media outlets to grossly exaggerate the costs of terrorist attacks...modern "soft news" publicizes these events to a larger audience.}

Ideological utility also factors into the way that terrorist organizations manipulate the targets' payoffs for cooperation. Intergroup bias, influenced by variables like ethnicity and beliefs, shapes support. ${ }^{19}$ Similarly, support is particularly high in regions where mutual cultural affinity is high. ${ }^{20} \mathrm{~A}$ terrorist organization can achieve cultural affinity by establishing an ideological link between its goals and society's preferences. An example of this concept is the Islamic link between organizations like al-Qaeda and their target populations. ${ }^{21}$ While al-Qaeda's conception of jihad is not reflective of Islam as a whole, it relies on extremist tenets of the religion in order to justify political action. By doing so, the organization can establish similarities with potential recruits and boost its chances of attaining cultural legitimacy in Islamic regions.

\section{Payoffs for Noncooperation}

The terrorist organization also decreases the target's payoff for noncooperation, $U(\bar{c}, \bar{c})$. The physical impact of a terrorist attack is usually minimal compared to other attacks like chemical, biological, nuclear, or conventional warfare.22 However, the physical damage from a terrorist attack is not the sole manipulator. Rather, fear is the mechanism through which attacks significantly impact the target. ${ }^{23}$ Consider, for example, the psychological effects on the American public after Oklahoma City bombings; the public perceived terrorism as a higher security risk after the attack. ${ }^{24}$ Some individuals even experienced symptoms of PTSD after watching attacks like $9 / 11$ and the Boston Marathon bombings on television. ${ }^{25}$
Terrorism, in that sense, works through the medium of fear in order to inflict costs.

Media can act as a cost multiplier because it disperses fear throughout the target's population. Media assessments of risk are based on the desire to sell drama to consumers. ${ }^{26}$ Therefore, there is an incentive for media outlets to grossly exaggerate the costs of terrorist attacks. Furthermore, modern "soft news" publicizes these events to a larger audience. ${ }^{27}$ It is important, of course, to consider the effects that the target's framing, priming, and indexing have on the quality of coverage, as biases in rhetoric may skew the media multiplier. ${ }^{28}$ All of these variables, linked with media coverage, affect to what extent the terrorist organization can disseminate fear through costly action.

Now that I have clearly outlined the mechanism with which terrorism coerces its target, I will illuminate how terrorist organizations' strategies of attrition and intimidation can manipulate costs through fear. ${ }^{29}$ The attrition strategy is intended "to persuade the enemy [target] that the group is strong and resolute enough to inflict serious costs, so that the enemy yields to the terrorists' demands". ${ }^{30}$ Attacks by Hezbollah and Hamas against Israel during the second Intifada correspond with this tactic, as the organizations sought to increase the human costs associated with noncooperation. Therefore, terrorist organizations pursuing the attrition strategy propagate the fear that the costs of a policy will outweigh the benefits in the long run. 


\section{The Alfred P. Murrah Federal Building after being targeted by the Oklahoma City bombers.}

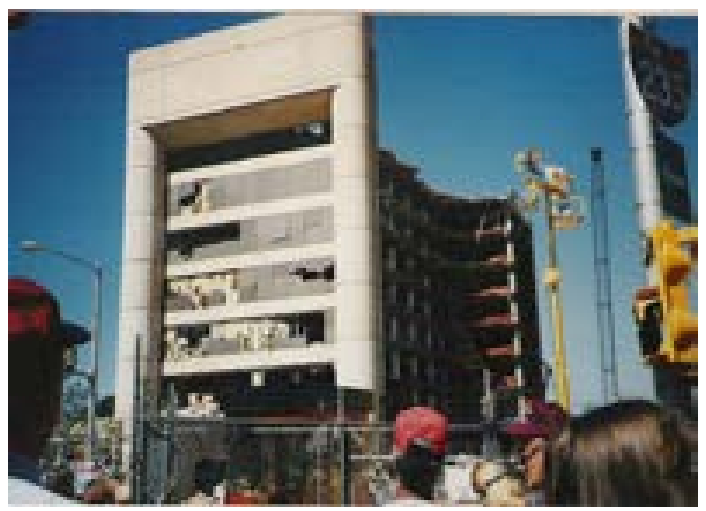

Intimidation also acts as a deterrent by threatening future costs if the target deviates from cooperation. ${ }^{31}$ A terrorist organization signals credibility and capacity to impose future costs with (1) violence and (2) charged rhetoric. As Criado illustrates, "violence can be a sign of the terrorist group's strength, and therefore, its bargaining position with the government". ${ }^{32}$ An increase in violence symbolizes commitment and credibility. Suicide terrorism, for example, is one of the more aggressive tactics in a terrorist's arsenal because it signals to the target that the issue is more important than the terrorist's life. ${ }^{33}$ The conditions around suicide terrorism can be manipulated to portray an "act of martyrdom", adding credibility to the act by attributing it to an ongoing political campaign.

Charged rhetoric intimidates the target by signaling continued potential for future attacks. Renewed threats can demonstrate the organization's commitment to existence. The Taliban in Afghanistan, for example, recently declared a renewed offensive for the spring of $2015 .{ }^{34}$ In this way, the Taliban demonstrated their continued commitment to imposing their ideal political world. Furthermore, delegitimizing the target bolsters perceived moral dominance. Osama bin Laden's scathingly charged that US concessions after the Beirut attack illustrated a US lack of courage. ${ }^{35}$ In this way, bin Laden sought to demonstrate moral superiority in order to inflate his organization's end-goal of dominating the US. Both of these tactics are ways that the terrorist organization convinces the target that punishment follows deviation.

\section{Susceptibility to Imposed Costs}

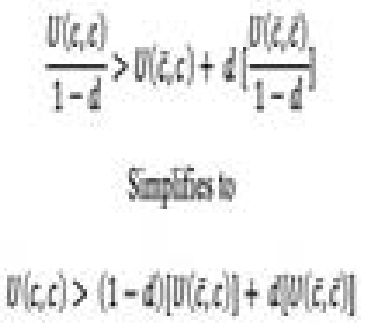

In the simplified inequality, we can see that $U(\overline{C, C})$ is weighted by $d$ (given $0<d<1$ ). By solely analyzing the expression $d\left[U\left(\overline{c^{\prime}, \bar{c}}\right)\right]$, we can determine how $d$ will affect the magnitude of a given change in the costs of not cooperating. Let us assume that the terrorist organization decreases the target's payoffs for noncooperation, $U\left(\overline{\left.c^{-}, C^{-}\right)}\right.$. The decrease in utility will be weighted more in the inequality if $d$ is a higher value. Recall that $d$ is the discount factor, or amount that the target values future payoffs (as $d$ approaches 1.0, the target appreciates future payoffs more). Therefore, changes in the target's payoff for noncooperation create more of an impact on the target that values long-term payoffs; fear hurts more when you care about the future.'

Walter illustrates that more democratic 


\section{The costs imposed by terrorist organizations affect democratic targets more significantly than they affect authoritarian targets.}

targets, in fact, value long-term payoffs more; therefore, they cannot as easily shoulder the costs of terrorist attacks. Free media, competing to dramatize impactful terrorist attacks, disperses the fear amongst the population, resulting in the people "demand[ing] an end to the attacks". ${ }^{36}$ The fear of being attacked, coupled with casualty aversion, places significant audience costs on politicians, who thus are incentivized to concede more in the infinite struggle against terrorism ${ }^{36}$ Furthermore, the majority of political assassinations and suicide bombings occur against democracies, implying that terrorist organizations understand that democracies are more susceptible to these costs. ${ }^{37}$ The infinite bargaining model complements the evidence that the costs imposed by terrorist organizations affect democratic targets more significantly than they affect authoritarian targets.

\section{Conclusion}

For a given goal, a terrorist organization bargains with a target long-term by increasing the payoffs for cooperation and decreasing the payoffs for noncooperation. From providing political, economic, social, and ideological utility to engendering the fear of future attacks, terrorists calculatingly coerce a target toward long-term cooperation. By doing so, they seek to not only achieve immediate concessions, but also to sustain increased bargaining capacity in the future. I hope that this model will provide a basis for assessing terrorist organizations as rational long-term actors in the sphere of international relations. Furthermore, I anticipate that this model may be used as a springboard for future research, such as how counterterrorism, antiterrorism, and counterinsurgency mitigate utility manipulation by the terrorist organization.

Free media, competing to dramatize impactful terrorist attacks, disperses fear amongst the opulation...the fear of being attacked, couple with casaulty aversion, places significant audience costs on politicians. 